\title{
PARTY HOSTS, INTOXICATED GUESTS AND NEGLIGENCE
}

\section{Ray Ryan, Barrister-at-Law and Des Ryan, Trinity College Dublin}

\begin{abstract}
In Donoghue v Stevenson, the House of Lords . . . recognized the existence of a "general conception of relations giving rise to a duty of care, of which the particular cases found in the books are but instances" (page 580, per Lord Atkin). The general concept of a duty owed to those whom one might injure proved both powerful and practical. However, it brought with it a question - a question we wrestle with to this day. How do we define the persons to whom the duty is owed? ${ }^{1}$
\end{abstract}

\section{Introduction}

On New Year's Eve, 1998, Julie Zimmerman and Dwight Courrier hosted a party at their home in Ottawa, Canada. The event was a "BYOB" ("bring your own booze") gathering combined with a "potluck supper". The only alcohol served by the hosts was three-quarters of a bottle of champagne in one-and-a-half-ounce glasses at midnight. Among their guests was Courrier's long-time friend Desmond Desormeaux, who was known to be a heavy drinker and who had previous convictions for impaired driving. He enjoyed the hosts' hospitality for approximately two and a half hours. During that time, he consumed twelve beers that he had brought with him. When Desormeaux walked to his car to leave the party, Courrier accompanied him and asked, "Are you okay, brother?" Desormeaux responded "No problem", got behind the wheel and drove away. He was accompanied by two passengers, his girlfriend and another friend, both of whom had attended the party and who were by this time intoxicated. Owing to his own intoxication, Desormeaux veered out of his own lane and collided head-on with another vehicle. One occupant of the other car was killed and another, Zoe Childs, then a teenager, was left paralysed from the waist down. Desormeaux pleaded guilty to a series of criminal charges arising from these events and received a 10-year sentence.

Childs instituted proceedings in negligence against both Desormeaux and the party hosts. She claimed that the party hosts, Zimmerman and Courrier, had a legal duty to prevent Desormeaux from driving while intoxicated. The core question to be resolved in the case - which was appealed all the way to the Supreme Court of Canada - was thus whether social hosts owe a duty of care in negligence to third parties injured by guests who have consumed alcohol on the hosts' premises.

At trial, Chadwick $\mathrm{J}$ held that a reasonable person in the position of the party hosts would have foreseen that Desormeaux might cause an accident and injure someone else. ${ }^{2}$ Accordingly, the hosts owed Childs a duty of care

1 Per McLachlin CJ in Childs v Desormeaux ("Childs") [2006] SCC 18 [2006] 1 SCR 64 [9].

2 (2002) 217 DLR (4th) 217. 
because they were aware of Desormeaux's history of alcoholism; the resulting harm to Childs from Desormeaux's actions was therefore reasonably foreseeable. However, the prima facie duty of care to which this finding gave rise was negatived, in the view of Chadwick $J$, by policy considerations. Such policy considerations included, inter alia, the "inordinate burden" which the imposition of a duty of care would place on all social hosts. ${ }^{3}$ An appeal to the Ontario Court of Appeal was dismissed, where an even more restrictive approach was taken: the appeal court ruled that the circumstances did not disclose even a prima facie duty of care. ${ }^{4}$ From this judgment Childs further appealed to the Supreme Court of Canada, urging the Court to impose a duty of care upon a social host in such a situation.

\section{Part I: Judgment of The Supreme Court Of Canada}

In approaching this question McLachlin CJ, delivering the judgment of a unanimous Court ${ }^{5}$, identified social host liability as a "novel" situation in which it was sought to impose a duty of care, not analogous to any existing duty of care. She observed that the closest parallel - that of imposing a duty on commercial alcohol providers to third-party road-users who are injured as a result of the drunken driving of a patron ${ }^{7}$ - was not a truly analogous situation. This was because there were significant differences between social and commercial hosts that made extending these duties, without regard to the dissimilarities between the parties, inappropriate. The Court identified three core differences between commercial and social hosts which justified the imposition of a duty of care on the former, but not the latter. These three core differences identified by the Court were as follows:

- supervising consumption of alcohol is an inherent function of the commercial host;

- the parameters of a commercial host's responsibilities are clearly articulated through legislation; and

- the benefit that commercial hosts derive from the sale of alcohol, namely profit, justifies the imposition of a duty to monitor its consumption for the public good.

3 ibid., at 243.

4 (2004) 239 DLR (4th) 61. The judgment of the Court, which was delivered by Weiler JA did, however, contain an important qualification: the Court was careful to stress that its judgment did not mean that social hosts were immune from liability to third party users of the road for damage caused by impaired guests who drive a car. Weiler JA explained that he did "not foreclose social host liability particularly when it is shown that a social host knew that an intoxicated guest was going to drive a car and did nothing to protect innocent third parties" (at 67).

5 Bastarache, Binnie, LeBel, Deschamps, Fish and Abella JJ concurring.

6 Childs, at [23]. In so doing, McLachlin CJ was in agreement both with Chadwick J at first instance and with the Ontario Court of Appeal.

7 Stewart v Pettie [1995] 1 SCR 131. 


\section{Northern Ireland Legal Quarterly [Vol. 58, No. 1]}

\section{Commercial Hosts v Social Hosts}

It is instructive to consider how each of these three characteristics of commercial hosts was regarded by the Supreme Court of Canada as warranting a different approach to the question of whether a duty of care should be imposed upon social hosts.

(i) Supervising consumption is an inherent function of the commercial host

A number of different points were noted by the Court in regard to this supervisory function of commercial hosts. Not only was monitoring of alcohol consumption relatively easy for a commercial host - it was actually expected by the host, patrons and members of the public. Furthermore, there was a "special incentive" for commercial hosts to monitor consumption since they are paid for service. Finally, those serving alcohol could generally be expected to possess special knowledge about intoxication. ${ }^{8}$ According to the Court, all of these points illustrated the marked difference, in terms of supervisory function, between social and commercial hosts.

(ii) Commercial hosts are strictly regulated by legislation and bear a special social responsibility

The second distinctive feature surrounding commercial host liability identified by the Court was that the commercial sale of alcohol is strictly regulated by legislation. The Court identified such regulation as not only being "driven by public expectations and attitudes towards intoxicants", but also serving, in turn, "to shape those expectations and attitudes". 9 The social responsibility of those who sell alcohol for profit was heavily stressed, with the Court observing that this social responsibility has many "very real and visible manifestations". ${ }^{10}$ Examples included the practice of imposing of a "cut-off" at the bar and the employment of "bouncers" to monitor admission and to assist other members of staff who might have to deal with intoxicated patrons. The Court noted that these features have no equivalent in the noncommercial context: "a party host has neither an institutionalized method of monitoring alcohol consumption and enforcing limits, nor a set of expectations that would permit him or her to easily do so". ${ }^{11}$

(iii) There is a contractual relationship between commercial hosts and patrons

For the Court, the third distinguishing feature of commercial host liability was the contractual nature of the relationship between a commercial host serving alcohol and a patron consuming it. This structured relationship was said to be "fundamentally different" from the range of different social relationships that can exist between persons hosting and attending private parties. A key feature of the contractual relationship between commercial hosts and patrons was that profit is to be gained by the host from the contractual relationship. As a result, "[u]nlike the host of a private party, commercial alcohol servers have an incentive not only to serve many drinks, but to serve too many. Over-consumption is more profitable than responsible

8 Childs, at [18].

9 ibid., at [19].

10 ibid., at [21].

11 ibid. 
consumption." ${ }^{12}$ In addition, the costs of such over-consumption must be borne by the drinker himself or herself, by taxpayers and, sometimes tragically, by blameless third parties who may meet inebriated patrons on the roads. Conversely, the benefits of over-consumption - in the form of hefty profit margins - go to the commercial host alone. The existence of such a "perverse incentive" 13 for commercial alcohol providers was said to support the imposition upon such providers of a duty to monitor consumption in the interests of the public.

The three core differences outlined above persuaded the Court that the existence of a duty on the part of commercial providers of alcohol could not be extended by simple analogy to private party hosts. Accordingly, the Court concluded that the duty proposed in Childs was novel, and fell to be assessed on an application of the two-stage $A n n s^{14}$ test, the test for establishing the existence of a duty of care which still applies in Canada. ${ }^{15}$

\section{Application of the Duty of Care test to Social Hosts in Childs}

On consideration of the first stage of Anns, the Court concluded that the necessary proximity had not been established and, consequently, that social hosts of parties where alcohol is consumed do not owe a duty of care to third-party road-users. Two reasons were offered for this conclusion. First, the injury to Childs was not reasonably foreseeable on the facts as found by the trial judge. Second, even if foreseeability were established, no duty would arise because the wrong alleged was a failure to act, or nonfeasance, in circumstances where there was no positive duty to act. ${ }^{16}$ We now consider the Court's basis for each of these reasons in turn.

\section{Foreseeability}

As noted, the Court rejected the argument of Childs that the parties were linked by the foreseeability of physical harm due to the manner in which the party hosts exercised "control or influence over" the party at which Desormeaux was drinking. McLachlin CJ noted that the question of foreseeability was complicated by certain ambiguities of fact in the findings at first instance. For example, the trial judge had found that Desormeaux would have been displaying "obvious signs of impairment" after consuming twelve beers, but since there had been no finding that the hosts actually knew, or ought to have known, that the guest who was about to drive was impaired, McLachlin CJ did not accept that it could be said that they should have foreseen that allowing him to drive might result in injury to other motorists. ${ }^{17}$

ibid., at [22].

13 ibid.

14 Anns v Merton London Borough Council [1978] AC 728.

15 The Anns test was confirmed as representing Canadian law by the Supreme Court of Canada in City of Kamloops v Nielsen [1984] 2 SCR 2, and further endorsed, albeit with some modification, recently in Cooper v Hobart [2001] 3 SCR 537. For valuable comment see, e.g. Neyers (2002) 118 LQR 221.

16 Childs, at [26].

17 ibid., at [28]. 
In this regard, two interesting features of the factual background to Childs should be noted. The first is that the hosts knew that Desormeaux had become drunk in the past and had then driven. The trial judge inferred from this that they should have foreseen that unless Desormeaux's drinking at the party was monitored, he would become intoxicated, get into his car and drive onto the highway. The Supreme Court of Canada rejected this inference. McLachlin CJ rejected the proposition that a history of alcohol consumption and impaired driving makes impaired driving, and the consequent risk to other motorists, reasonably foreseeable. She continued as follows: ${ }^{18}$

"The inferential chain from drinking and driving in the past to reasonable foreseeability that this will happen again is too weak to support the legal conclusion of reasonable foreseeability - even in the case of commercial hosts, liability has not been extended by such a frail hypothesis."

The second important feature of the background to Childs was that one of the hosts, Courrier, had accompanied Desormeaux to his car before the latter drove away from the party. Could this degree of contact with an intoxicated guest not give rise to the conclusion that the host would foresee the likelihood of harm being caused by the guest? Once again, this argument was rejected by the Supreme Court, principally because there had been no finding at first instance that Desormeaux had displayed signs of intoxication during this brief encounter.

\section{Nonfeasance}

The Supreme Court identified the "real complaint"19 in Childs in the following terms: that having organised the party, the hosts failed to prevent their guests from driving when intoxicated. In approaching its consideration of whether such circumstances could give rise to a duty of care in negligence, the Court emphasised the limited circumstances in which the law of negligence will impose a positive duty to act. Such situations are governed by special characteristics of the relationship between the plaintiff and the defendant which establish proximity. McLachlin CJ cited examples from decisions of the Canadian courts imposing such a duty where a defendant intentionally attracts and invites third parties to an inherent and obvious risk that he or she has created or controls ${ }^{20}$; where paternalistic relationships of supervision and control, such as those of parent-child or teacher-student, exist ${ }^{21}$; and where a defendant either exercises a public function or engages in a commercial enterprise that includes implied responsibilities to the public at large..$^{22}$ Surveying the caselaw, the Court noted that three themes pervaded

18 Childs, at [29].

19 ibid., at [33].

20 The Canadian authorities cited by McLachlin CJ in support of this proposition were Hendricks v The Queen [1970] SCR 237; Horsley v MacLaren [1972] SCR 441; Arnold v Teno [1978] 2 SCR 287; and Crocker v Sundance Northwest Resorts Ltd. [1988] 1 SCR 1186.

21 Relevant Canadian authorities on point, and cited in the judgment of the Supreme Court of Canada in Childs, include Dziwenka $\mathrm{v}$ The Queen in right of Alberta [1972] SCR 419; Bain v Board of Education (Calgary) (1993) 146 AR 321.

22 Canadian authorities cited in support of this proposition were Dunn v Dominion Atlantic Railway Co. (1920) 60 SCR 310; Jordan House Ltd. v Menow [1974] 
the jurisprudence in which liability in negligence is imposed for a failure to act. The first theme was the defendant's "material implication in the creation of risk or his or her control of a risk to which others have been invited". ${ }^{23}$ The second was a concern for the autonomy of the persons affected by the positive action proposed. As a general rule, the individualistic philosophy underlying the common law militates against the imposition of a duty to eliminate risk. The law "accepts that competent people have the right to engage in risky activities". ${ }^{24}$ The law will only impinge upon individual autonomy when a special relationship or nexus exists or when the defendant has a material role in the creation or management of the risk which has eventuated. The final theme in the three paradigm cases of liability for nonfeasance identified by the Court, and outlined above, was the theme of reasonable reliance. Two questions thus fell to be considered: did the relationship between party hosts and their guests come within the scope of any of the three categories outlined above? If not, did it constitute an appropriate extension of them having regard to the three themes that underscore them?

The Supreme Court of Canada answered both questions in the negative. The Court first rejected the notion that a private social party fell within any of the three categories outlined above: holding a party - although it certainly may involve some risks - was not especially risky and was "a far cry from inviting participation in a high-risk sport or taking people out on a boating party"25; secondly, since it was a gathering of one's peers there was no element of paternalism or power imbalance; and, thirdly, there was clearly no public element to the relationship between party hosts and their guests. Hence, the situation at issue in Childs did not fall within one of the established categories of cases in which it had been held to be appropriate to impose a positive duty to act.

The remaining question - whether the underlying themes present in cases of liability for nonfeasance also applied in this case - was again answered in the negative. Each theme in turn was considered but none was said to encapsulate the relationship at issue between the parties in Childs.

The first theme of special risk creation was held inapplicable to the facts of Childs. In holding a private party, the host "creates a place where people can meet, visit and imbibe alcohol, whether served on the premises or supplied by the guest", all of which "falls within accepted parameters of nondangerous conduct". ${ }^{26}$ Significantly, McLachlin CJ left open the possibility that a duty of care may be imposed upon a host who continues to serve alcohol to a visibly intoxicated person knowing that he or she will be driving home, since the host would have "become implicated in the creation or enhancement of a risk sufficient to give rise to a prima facie duty of care to third parties" 27 , though this would be subject to a consideration of contrary

SCR 239; Jane Doe v Metropolitan Toronto (Municipality) Commissioners of Police (1998) 39 OR (3d) 487.

23 Childs, at [38].

24 ibid., at [39].

25 ibid., at [42].

26 ibid., at [44].

27 ibid., at [44]. See above n.4. 
policy considerations at the second stage of the Anns test. This point was expressly left open in the judgment of the Supreme Court of Canada in Childs. But it was very clearly stated that hosting a party where alcohol is served or consumed, without more, does not amount to the creation or exacerbation of risk of the level required to impose a duty of care on the host to members of the public who may be affected by a guest's conduct.

Similarly, the theme of respect for individual autonomy running throughout the caselaw militated against the imposition of a duty in Childs. A party guest was no less responsible for his or her conduct simply by accepting, without more, an invitation from a host. Moreover, the consumption of alcohol - coupled with the attendant assumption of risks of inebriation - was "a personal choice and an inherently personal activity". ${ }^{28}$ Outside the special considerations existing in the commercial context outlined above, an adult who voluntarily decided to consume alcohol must bear responsibility for the outcomes of that decision. The individualist philosophy on which this aspect of the judgment was based was memorably captured by McLachlin CJ when she commented that " [a] person who accepts an invitation to attend a private party does not park his autonomy at the door". ${ }^{29}$ Finally, the issue of public reliance was deemed to be of no relevance in a private context, and the lack of any reliance by party guests on monitoring by their hosts again only underlined the distinction between commercial hosts and private hosts.

\section{Part II : Analysis}

Before considering the policy arguments invoked to deny the duty of care in Childs, a number of preliminary points should be made. First, it should be noted that the Supreme Court of Canada has recently confirmed ${ }^{30}$ that the appropriate test in that jurisdiction for establishing whether a duty of care exists is the two-stage test famously enunciated by Lord Wilberforce in Anns v Merton London Borough Council. ${ }^{31}$ As is well known, other courts have long since rejected the continued application of Lord Wilberforce's test and have supplanted it with the three-stage inquiry involving a consideration of whether it is "fair, just and reasonable" to impose a duty. This three-stage test was confirmed as representing the correct test for establishing a duty of care by the House of Lords in Caparo Industries plc $\mathrm{v}$ Dickman. ${ }^{32}$ The test comprises the following inquiry articulated by Lord Bridge:

"What emerges is that, in addition to the foreseeability of damage, necessary ingredients in any situation giving rise to a duty of care are that there should exist between the party owing the duty and the party to whom it is owed a relationship characterised by the law as one of 'proximity' or 'neighbourhood' and the situation should be one in which the court considers it fair, just and reasonable that the law should

28 ibid., at [45].

29 ibid.

30 See above n. 15 .

31 [1978] AC 728.

32 [1990] 2 AC 605. Compare Sutherland Shire Council v Heyman (1985) 157 CLR 424 (High Court of Australia) and Glencar Explorations plc v Mayo County Council (No.2) [2002] 1 IR 84 (Irish Supreme Court). 
impose a duty of a given scope upon the one party for the benefit of the other." 33

Since the clear effect of the departure from Anns - and the introduction of the "incremental" approach to establishing whether a duty of care exists was to render it more difficult to establish a duty of care, it is submitted that the result in Childs will likely be followed in those jurisdictions in which Caparo applies. However, it is instructive to consider various aspects of the approach adopted by the Supreme Court of Canada in Childs in the event of similar cases falling to be determined in those other jurisdictions.

\section{Social Hosts v Commercial Hosts}

As discussed above, the Court emphasised a number of distinctions between social and commercial hosts warranting the existence of a duty of care on the part of the latter but not the former. Of the three grounds on which such a difference was justified - supervision, regulation and contract - it is respectfully submitted that the latter two grounds are the most convincing. As to the first - the ease with which supervision can be exercised by the commercial host - could it not be said that social hosts are in fact more likely than commercial hosts to know of their guests' susceptibility to (overindulge in) alcohol, and will likely have more opportunities to monitor their guests' state of sobriety given that they are likely to be interacting with them in the course of a party to an extent that would not normally be expected to pertain between a commercial host and a patron in a bar? ${ }^{34}$ Moreover, it might be thought that social hosts would enjoy a broader range of options to diffuse a potentially dangerous situation and to prevent an intoxicated guest from driving. Commonplace examples might be to encourage guests to defer departure until the following morning; to arrange for guests to be escorted home by a fellow party guest who has not consumed alcohol; at parties where the guest is serving alcohol, to combine this with the serving of food and to cease serving alcohol some time before the party ends.

McLachlin CJ stressed the expectation of the general public that commercial hosts will monitor consumption. But it is respectfully submitted that this emphasis is somewhat undermined by her recognition that commercial hosts have a "perverse incentive" to oversupply alcohol to their customers: if this perverse incentive is such a live threat to patrons, then can it meaningfully be said that members of the public expect a commercial host to encourage - and to demand from its customers - restraint in consumption?

Considering the commercial/social host distinction posited in Childs, it is important to note that the imposition of a duty of care even upon commercial

33 [1990] 2 AC 605, at 617-618.

34 This point was implicitly noted by Gleeson CJ in the High Court of Australia in declining to impose liability upon a commercial host in South Tweed Heads Rugby League Football Club Ltd (2004) 217 CLR 469 where Gleeson CJ observed at [12]: "The capacity of a supplier of alcohol to monitor the level of risk to which a consumer may be exposed is limited. If a restaurant proprietor serves a bottle of wine to two customers at a table, the proprietor may not know what either of them has had to drink previously, the proportions in which they intend to share the bottle, or what they propose to do when they leave the restaurant. Few customers would take kindly to being questioned about such matters." 
hosts remains far from settled across the common law world. Thus in Cole v South Tweed Heads Rugby League Football Club Ltd ${ }^{35}$ the majority of the High Court of Australia recently declined to impose a duty of care in a commercial alcohol provider case, with only two members of the Court (Kirby and McHugh JJ) finding that there was a duty of care in the case of commercial providers. ${ }^{36}$

A similarly cautious approach in the context of commercial hosts was evinced by the Northern Ireland Court of Appeal in Joy v Newell ( $t / a$ The Copper Room). ${ }^{37}$ Although Joy concerned an action brought by a guest himself rather than a third party, the case is nonetheless relevant in the context of the present debate in terms of the attitude evinced by the Court to the relationship between alcohol providers and their guests. In that case, the plaintiff entered the defendant's bar in an intoxicated state, sat on a bar stool and ordered a drink. After a couple of sips, he fell off the stool and sustained injuries that caused paralysis. The plaintiff brought an action in negligence against the publican, arguing that the latter owed him a special duty of care because of the nature of the licensee and customer relationship, which meant that the publican had a positive duty to ensure the plaintiff's safety on his premises. The plaintiff contended that the positive duty had been breached by his being permitted to use a stool in his intoxicated state. At first instance ${ }^{38}$, it was held that, although the defendant owed a positive duty of care by virtue of his licensee status, this had not been breached in the instant case. The Northern Ireland Court of Appeal dismissed the appeal. Carswell LCJ (as he then was) held that a positive duty to save someone from danger only arose where there had been an assumption of responsibility to ensure that person's safety. Despite it being a criminal offence for a licensee to serve alcohol to an obviously intoxicated customer, it was unreasonable to assume that a licensee had assumed a positive duty on the basis that a customer could become so drunk that he would be unable to take care of himself. It had not been proved that either the defendant or his barman knew the extent of the plaintiff's intoxication.

Clearly this latter point echoes the qualification entered by McLachlin CJ in Childs in the context of social hosts, that is, that a duty could arise where the host knew the extent of the guest's intoxication. The decision in Joy v Newell would suggest that the courts in Northern Ireland will be slow indeed to impose liability even on a commercial host in the absence of clear and

35 (2004) 217 CLR 469. For comment see Orr and Dale, "Impaired judgements? Alcohol server liability and 'personal responsibility' after Cole v South Tweed Heads Rugby League Football Club Ltd" [2005] TLJ 7.

36 See the judgment of Kirby J at [90] - [93] and that of McHugh J at [31]. Gummow and Hayne JJ specifically reserved (at [81]) their position as to whether or not there was a duty of care owed by commercial hosts. Significantly, even if there had been a duty of care on the defendant club, Gummow and Hayne JJ expressed the view that on the facts of Cole the duty would have been met merely by offering to provide a courtesy means of transport home to the intoxicated patron (at [80]). Gleeson CJ and Callinan J, in separate judgments, agreed that there had been no breach of duty, and went further in holding that no duty of care arose in the circumstances of the case. See above n.34, and the judgment of Gleeson CJ at [18] and that of Callinan $\mathbf{J}$ at [131].

37 [2000] NI 91.

38 [1998] NIJB 111. 
manifest assumption of responsibility. In so holding, the Northern Ireland Court of Appeal approved and applied the decision of the Court of Appeal in Barrett $\mathrm{v}$ Ministry of Defence, ${ }^{39}$ a decision evincing a similar reluctance to impose liability upon commercial hosts. Having also considered, inter alia, relevant jurisprudence from both the Supreme Court of Canada and from Australian courts, the Court concluded that it was "not attracted" by these authorities which were apt to impose an "unreasonable burden on licensees". 40

\section{Misfeasance or nonfeasance?}

As we have seen, the complaint in Childs was characterised as involving a question of nonfeasance: the hosts did not commit an act of carelessness, but rather failed to perform a positive act of preventing another person from driving. We have seen that McLachlin CJ characterised the holding of a private party as a situation in which the host "creates a place where people can meet, visit and imbibe alcohol, whether served on the premises or supplied by the guest", all of which "falls within accepted parameters of nondangerous conduct". ${ }^{41}$ This categorisation of the hosts' role as one of nonfeasance may, however, be questioned. It can legitimately be said that the hosting of a party and the provision of a forum in which alcohol will be consumed constitutes an activity involving foreseeable risks of overconsumption. The effects of over-consumption are sufficiently well known for it to be deemed common knowledge that such an event carries with it the potential for injuries to guests - and to innocent third parties whom such guests will meet if they drive away from the party venue. Accordingly, is not the decision to undertake the staging of such an event indeed (despite the contrary position adopted by the Supreme Court of Canada $^{42}$ ) a decision to undertake to "create a risky situation and invite others into it"?

Another curious feature of the "nonfeasance" position adopted by the Supreme Court of Canada in Childs is that the findings of fact made by the trial judge - which were not disturbed at either level of appeal - included a determination that he was "satisfied on the evidence that Dwight Courrier deliberately did not pay any attention to how much alcohol was brought in by the Desormeaux group or how much was consumed while on the premises." ${ }^{3}$ With respect, it is not altogether obvious how such a finding could lead to the conclusion that the facts of Childs amounted to nonfeasance - particularly since both Zimmerman and Courrier knew that Desormeaux had a propensity to over-indulge in alcohol, and Courrier escorted Desormeaux to his vehicle and thus knew that his guest was driving away.

Nor should the misfeasance/nonfeasance question necessarily be answered by consideration of whether the social party was one at which guests provided their own alcohol. As we have seen, in Childs the hosts had not provided alcohol save for small celebratory glasses of champagne at

9 [1995] 1 WLR 1217.

40 [2000] NI 91, 102.

41 Childs, at [44].

42 ibid., at [35].

43 ibid., at [67]. 
midnight; the event was a "BYOB" gathering. The sole object of organizing a "BYOB" party is presumably to relieve the host(s) of the expense and inconvenience of supplying alcohol for all guests; beyond this, the host-guest dynamic remains intact and the event loses nothing of its original character: the gathering together of one's friends to socialise while consuming alcohol. Whether or not that gathering will itself give rise to the imposition of a duty of care in negligence is a question which remains far from settled in many common law jurisdictions. The Supreme Court of Canada with its judgment in Childs has in principle answered "No", though expressly recognising that certain instances may arise in which liability could be imposed.

\section{Autonomy}

As already noted, the Supreme Court of Canada in declining to impose a duty of care in negligence placed particular emphasis on personal autonomy and expressed concern lest such autonomy be diminished or eroded were the law to impose a duty of care upon social hosts in the position of the defendants in Childs. McLachlin CJ expressed in particularly strong terms her view that adult guests at a party must accept responsibility for their own conduct and the ramifications thereof. This aspect of the Court's judgment is redolent of an increasing tendency of courts in a number of jurisdictions to have regard to autonomy principles so as to prevent recovery in the law of torts. One clear example of just such a philosophy was the decision of the House of Lords in Tomlinson v Congleton Borough Council. ${ }^{44}$ It will be recalled that the claimant in Tomlinson suffered a serious injury when he dived into a park lake and struck his head on the bottom. He sued the defendant occupiers of the park. The House of Lords unanimously agreed that the defendants were not liable. The philosophy of Tomlinson was memorably captured by Lord Hobhouse in the following forceful passage ${ }^{45}$ of his opinion:

"In truth, the arguments for the claimant have involved an attack upon the liberties of the citizen which should not be countenanced. They attack the liberty of the individual to engage in dangerous, but otherwise harmless, pastimes at his own risk and the liberty of citizens as a whole.... The pursuit of an unrestrained culture of blame and compensation has many evil consequences and one is certainly the interference with the liberty of the citizen."

The general principle running through cases such as Childs and Tomlinsonthe importance of individual autonomy - arguably militates against the recognition of a duty of care of the kind contended for in Childs. There, the Supreme Court of Canada fastened on the principle that "the common law is a jealous guardian of individual autonomy". ${ }^{46}$ It is perhaps ironic that although in recent years autonomy values have been consistently canvassed with a view towards achieving redress in tort law, ${ }^{47}$ Childs illustrates that

44 [2004] 1 AC 46.

45 ibid., at 97.

46 Childs, at [31].

47 Two notable examples are the majority decisions of the House of Lords in Rees $\mathrm{v}$ Darlington Memorial Hospital NHS Trust [2004] 1 AC 309 and Chester v Afshar 
concerns about the promotion of autonomy can, too, be identified so as to disallow recovery through the vehicle of tort law.

\section{Conclusion}

We have seen that the decision in Childs was restrictive in nature and declined to extend liability in negligence to the social hosts in that case. Even if the approach in Childs is followed in other jurisdictions, however, there may still exist a number of situations in which social hosts could be held liable in negligence for the acts of their intoxicated guests. In this regard, a number of points occur from an analysis of the judgment in Childs. First, it is important to emphasise that the Supreme Court of Canada expressly reserved its position on whether a duty of care would exist in a situation where hosts are aware of the intoxicated state of their guest but nevertheless permit him or her to drive away intoxicated from a party. ${ }^{48}$ Furthermore, the reference by McLachlin $\mathrm{CJ}$ to situations in which the social relationship is characterised by a paternalistic element - a characteristic which favours the imposition of a duty - suggests that a duty of care would likely be imposed upon, for example, parents who either invite or permit a group of teenagers to consume alcohol at a party. At a more conceptual level, it is of interest that the Court in Childs did not accept that a prima facie duty of care arose, then going on to consider any policy considerations which might have negated that duty. ${ }^{49}$ Should a similar case fall to be considered in those jurisdictions applying the Caparo test, it may be that the application of the first two limbs of that test could yield an affirmative answer to the question of whether a duty should be imposed, with the matter then being determined on the application of the ever-malleable "fair, just and reasonable" third limb..$^{50}$

[2005] 1 AC 134. The latter case was discussed by Heywood in (2005) 56 NILQ 266.

48 See above, text preceding n.27.

49 As we have seen, this approach had been taken by Chadwick J at first instance but was not adopted at either level of appeal. In both the Ontario Court of Appeal and the Supreme Court of Canada, the facts were deemed not to disclose even a prima facie duty under the first stage of the Anns test.

50 The malleability of this third limb was recently highlighted by the contrasting approaches of the House of Lords and the Court of Appeal in Commissioners of Customs and Excise v Barclays Bank [2006] UKHL 28; [2006] 3 WLR 1. 